Clinical Vistas

\section{Necrobiosis lipoidica diabeticorum}

A 22-year-old woman with type I diabetes presented with a Ioyear history of a yellow-red, telangiectatic plaque $7 \mathrm{~cm}$ in diameter with central atrophy on her left forearm (Figure I). The edges of the plaque were slightly elevated and the wound was excruciatingly painful. She had no known comorbidities, and previous topical corticosteroid therapy had been unsuccessful. We prescribed a more powerful steroid for topical use, which I was also unsuccessful. The long-term outcome is unknown because the patient was lost to follow-up.

Necrobiosis lipoidica was first described by Oppenheim in I929 as a chronic granulomatous dermatitis of unknown cause. The disease usually develops in patients aged 30-40 years and has a female:male ratio of $3: 1$. About $65 \%$ of patients with necrobiosis lipoidica also have diabetes, mostly type I, and its prevalence among diabetics has been estimated to be $0.3 \%{ }^{1}$ Necrobiosis lipoidica has also been associated with Crohn's disease, ulcerative colitis, granuloma annulare and sarcoidosis. ${ }^{1}$

Necrobiosis lipoidica diabeticorum most commonly appears on the shins, the back of the hands or the forearms as yellow-red plaques with telangiectatic vessels, central atrophy and raised violet-coloured edges. Ulcers, often induced by trauma, occur in 30\%

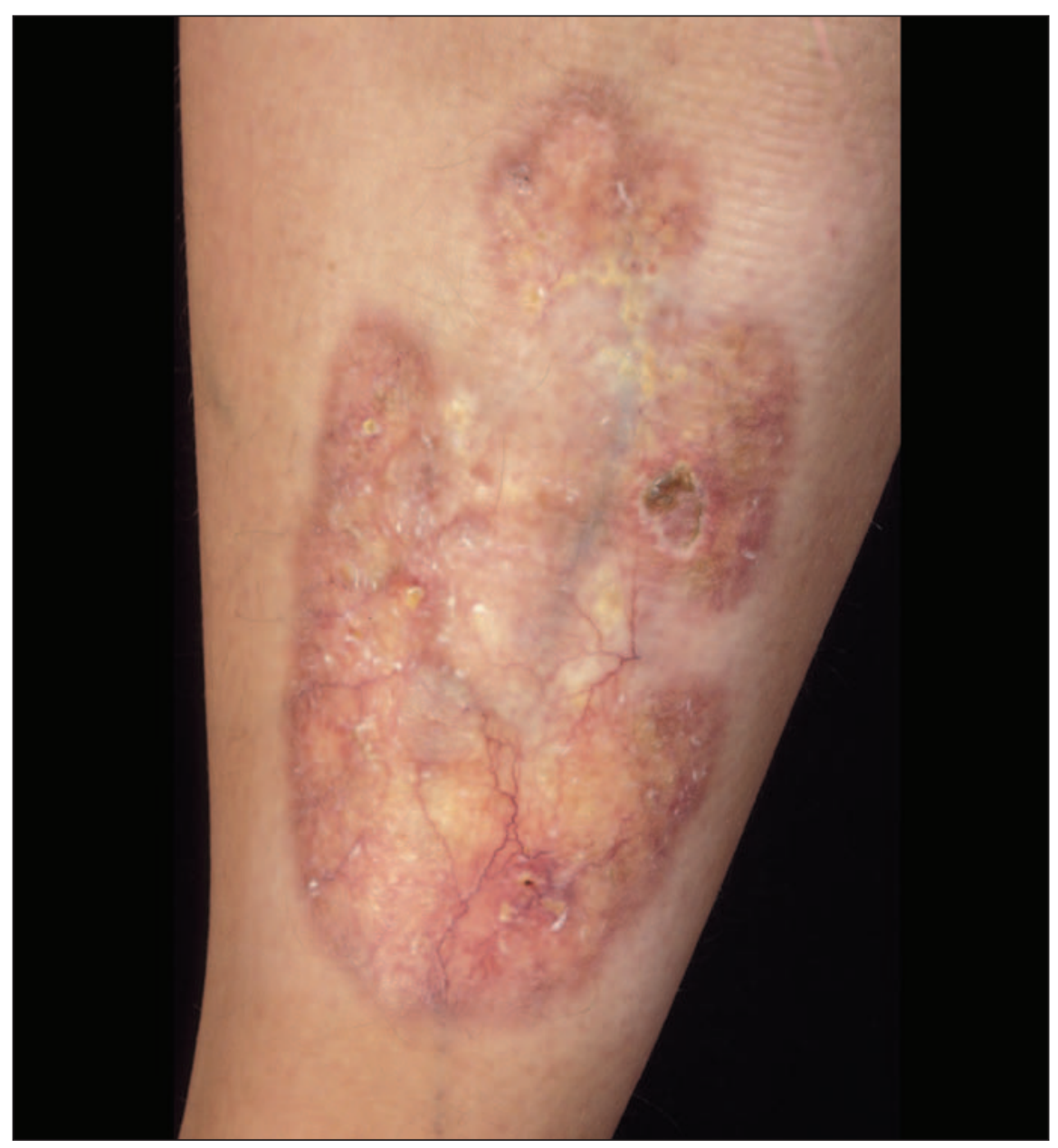

Figure 1: Papules extending to form a yellow-red plaque covered with telangiectatic vessels on the patient's forearm. of lesions. Rarely, squamous cell carcinoma has been reported in older lesions with ulceration. Histopathologically, the condition presents with interstitial and palisaded granulomas that involve the subcutaneous tissue and dermis. The infiltrate in the reticular dermis predominately consists of $\mathrm{CD} 4$ lymphocytes.

Currently, there are no evidencebased guidelines for the treatment of necrobiosis lipoidica diabeticorum. The condition is often resistant to therapy; however, spontaneous remission is reported in about $20 \%$ of patients. Therapeutic options include glucucorticoids, a combination of acetylsalicylic acid and dipyridamole, or psoralen plus ultraviolet A photochemotherapy. New treatment strategies include cyclosporin $\mathrm{A}$, infliximab or tacrolimus, which can be used topically or systemically. ${ }^{2,3}$ Use of infliximab leads to a reduction of the pro-inflammatory cytokine level and a decrease of the serum level of tumour necrosis factor-c. Cyclosporin A and tacrolimus inhibit interleukin-2, which in turn decreases the activity of $\mathrm{T}$ helper cells, regulatory $\mathrm{T}$ cells, natural killer cells and monocytes. Reports of successful systemic cyclosporin A and infliximab therapy indirectly support the hypothesis that T-cell-mediated immune processes play a role in pathogenesis. Non-Tcell-mediated effects of these therapies include reduced expression of adhesion molecules and histamine liberation. ${ }^{3}$ Further studies will be required to pinpoint the cause of necrobiosis lipoidica and to test specific therapies.

\section{Andreas Körber MD \\ Joachim Dissemond MD \\ Department of Dermatology \\ University of Essen \\ Essen, Germany}

Competing interests: None declared.

\section{REFERENCES}

I. Lowitt MH, Dover JS. Necrobiosis lipoidica. J Am Acad Dermatol 1991;25:735-48.

2. Aslan E, Körber A, Grabbe S, et al. Successful therapy of ulcerated necrobiosis lipoidica non diabeticorum with cyclosporine A. Hautarzt 2007;58:684-8.

3. Griffiths CEM, Katsambas A, Dijkmans BAC, et al. Update on the use of ciclosporin in immune-mediated dermatoses. Br J Dermatol 2006;155(Suppl 2):I-I6. 